\title{
Nuclear Magnetic Resonance for the Structural Study of Bioactive Semicarbazones
}

\author{
H. Cerecetto ${ }^{1}$, R. Di Maio ${ }^{1}$, M. González ${ }^{2}$, G. Seoane ${ }^{1}$, G. Sagrera ${ }^{2}$ and M. Millán ${ }^{3}$ \\ ${ }^{1}$ Cátedra de Química Orgánica, Facultad de Química \\ ${ }^{2}$ Laboratorio de Química Orgánica \\ ${ }^{3}$ Laboratorio de RMN, Facultad de Ciencias, Iguá S/N, Universidad de la República, Montevideo, \\ Uruguay \\ E-mail: megonzal@bilbo.edu.uy
}

Abstract: NMR studies of bioactive semicarbazones are described.

\section{Introduction}

Within our work on the development of bioactive compounds, we have employed the semicarbazone moiety as a joining function between different pharmacophores.<smiles>[R]NC(=O)N=Cc1ccc([N+](=O)[O-])o1</smiles><smiles></smiles><smiles>[R]NC(=O)N=Nc1ccc2nonc2c1</smiles>

Knowing the geometric isomer at the iminic union of the semicarbazone group, as well as the $N$ oxide positional isomer that was obtained in the synthetic procedure, were very important for determining the structure of the biologically active compound. The lack of crystals to determine unequivocally the exact structure of the product obtained led us to use NMR spectroscopy for this purpose.

\section{Experimental}

All the experiments were carried out on a DPX-Bruker 400 (400 y $100 \mathrm{MHz}$ ) instrument. We carried out NOE difference (1D y 2D) experiments at different mixing times in order to determine the geometric isomer of the iminic junction.

We also carried out ${ }^{1} \mathrm{H}-\mathrm{NMR}$ and ${ }^{13} \mathrm{C}-\mathrm{NMR}$ experiments at variable temperatures and EXSY experiments in order to determine the $\mathrm{N}$-oxide position.

\section{Results and Discussion}

All the semicarbazones studied were in the $E$ isomeric form. The $N$-oxide moiety in the derivatives 
of the heterocycle 1,2,5-oxadiazoles was found fixed at the 2 position. The derivatives of the heterocycle benzo[1,2-c]1,2,5-oxadiazoles were presented as a mixture of the different positional isomers of the $\mathrm{N}$-oxide function, at room temperature.

Acknowledgements: C.H.L.C.C., PEDECIBA.

\section{References and Notes}

1. Perrin, C.; Dwyer, T. Chem. Rev. 1990, 90, 935. 